\title{
Recent Insights into the Neurobiology of Impulsivity
}

\author{
Marci R. Mitchell • Marc N. Potenza
}

Published online: 20 September 2014

(C) Springer International Publishing AG 2014

\begin{abstract}
Impulsivity is associated with various psychopathologies, and elevated impulsivity is typically disadvantageous. This manuscript reviews recent investigations into the neurobiology of impulsivity using human imaging techniques and animal models. Both human imaging and preclinical pharmacological manipulations have yielded important insights into the neurobiological underpinnings of impulsivity. A more thorough understanding of the complex neurobiology underlying aspects of impulsivity may provide insight into new treatment options that target elevated impulsivity and psychopathologies such as addictions.
\end{abstract}

Keywords Impulsivity $\cdot$ Neuroimaging $\cdot$ Translational · Human $\cdot$ Rodent $\cdot$ Delay discounting

\section{Introduction}

Impulsivity can be described as "swift action without forethought or conscious judgment" [1,2], and it can be conceptually divided into multiple forms that may include self-report, response, and choice impulsivity. Self-report impulsivity refers to a more general impulsivity measure, or impulsivity as a personality trait, whereas response impulsivity is the inability to withhold a proponent response, and choice impulsivity

M. R. Mitchell $(\bowtie) \cdot$ M. N. Potenza

Department of Psychiatry, Yale University School of Medicine, 1

Church St, 7th floor, New Haven, CT 06510, USA

e-mail: marci.mitchell@yale.edu

\section{N. Potenza}

Department of Neurobiology, Yale University School of Medicine, New Haven, CT, USA

M. N. Potenza

Child Study Center, Yale University School of Medicine, New

Haven, CT, USA reflects an inability to delay gratification for a larger payout $[1,3]$. Different forms of impulsivity may factor separately from one another, raising questions regarding whether they form a unitary or distinct constructs. For example, choice and action impulsivity in both rats and healthy humans were not related to each other in either species [4•]. Multiple forms of impulsivity may be elevated within specific diagnostic groups [5-9]. For example, addictions are associated with elevated trait, action, and choice impulsivity [10-16]. Therefore, determining the underlying neurobiologies of specific domains of impulsivity may help understand the etiology, prevention, and treatment of addictions and other disorders. This review focusses on recent studies of impulsivity, particularly as related to addictions.

\section{Measures of Impulsivity}

Human Measures of Impulsivity

Self-report measures may be used to assess impulsive tendencies. A common assessment is the Barratt Impulsiveness Scale (BIS-11), which has been found to factor into three subscales, including attentional, motor, and non-planning impulsivity [17], although recent studies have identified different subscale patterns within different diagnostic groups (see Reid et al. [18]). The UPPS-P is another self-report measure that has been found to factor into five subscales (negative urgency, positive urgency, lack of premeditation, lack of perseverance, and sensation seeking) [19]. Some other measures of impulsivity may fall across several domains. For example, the Monetary Choice Questionnaire (MCQ or Kirby) measure assesses delay discounting by asking individuals to make choices between two hypothetical outcomes and may reflect trait/self-reported tendencies as well as choice impulsivity [14]. For example, would you rather have $\$ 50$ today or $\$ 75$ 
next month? Similar to behavioral delay-discounting tasks, discounting curves can be calculated, with steeper curves reflecting greater self-reported choice impulsivity.

In addition to measures that rely on self-report, computerized tasks have been developed to measure response impulsivity. Response impulsivity may be described as diminished control over action cancellation, although this definition may be more closely aligned with the stopping of an ongoing action (as assessed with the Stop Signal Task [SST]) than with the withholding of an initial response (as assessed with the Go/NoGo Task [GNG]). In the SST, participants are instructed to make a rapid response (e.g., button press) to a given cue (e.g., plus sign). After learning this requirement, participants are randomly and without warning given a 'stop' signal, which indicates that they should inhibit the rapid response [20]. The ability of participants to successfully cancel an action and the latency to do so are measured. Those who are considered impulsive tend to make more errors or have an increased latency in action cancellation. Similar to the SST, GNG participants are given two cues: a 'go' cue that signals they should perform a specified action (e.g., button press) and a 'no go' cue that signals they must inhibit the action [21]. Again, both reaction time and successful inhibition are measured. Individuals who have difficulty successfully inhibiting their response after the stop signal is presented display greater response impulsivity. There are several variations of the continuous performance task, which tax individuals' sustained attention [22], that have been associated with measures of impulsivity as task participants must respond or withhold responding to stimuli.

A third form of impulsivity is impulsive choice, which reflects a preference for smaller, sooner over larger, later rewards. The main measurement of impulsive choice employs delay-discounting tasks, during which individuals choose between two different rewards. Delay discounting describes the phenomena wherein the subjective value of a reward decreases (or is discounted) as the time to reward receipt becomes farther into the future $[23,24]$.

\section{Animal Measures of Impulsivity}

Response impulsivity is commonly measured in rodents using the five-choice serial reaction-time task (5CSRTT). In this task, rodents are placed into operant chambers and are required to scan five apertures on one wall of the chamber for the presentation of a brief target visual stimulus (e.g., light) in one of them. Immediately following stimulus presentation, the rodent is required to make a nosepoke response at that aperture to obtain a food reward. Rodents can commit several types of errors during the 5CSRTT, with 'premature errors' specifically linked with response impulsivity. These premature errors occur when the rodent responds in an aperture before the target stimulus has been presented, i.e., the rodent has failed to wait for the appropriate signal before making a response (for review see Dalley et al. [25]). More impulsive animals display a greater number of premature response errors.

Delay-discounting tasks, similar to those used in humans, have been developed to measure impulsivity in rodents. In these tasks, rodents are placed in operant chambers and presented with choices between a smaller, sooner reward or a larger, later reward. While human delay-discounting tasks typically use money as a tangible reward, rodent tasks typically use food or water as the reward. Greater discounting of the large reward (e.g. steeper discounting) is indicative of a more impulsive animal [26, 27].

\section{Underlying Neurocircuitry of Impulsivities}

Both clinical and animal studies investigating the neurobiological and psychopharmacological basis of impulsivity have focused on and heavily implicated monoaminergic corticostriatal systems [28]. Brain imaging studies in humans have identified structural and functional alterations in corticostriatal circuitry in impulsive individuals. In particular, dysfunctional or dysregulated monoaminergic signaling (most notably within the dopaminergic [DA] and serotonergic [5HT] systems) has been suggested to underlie both response impulsivity and impulsive choice.

\section{Self-Report}

In healthy humans, gray- and white-matter volumes have been found to correlate with scores on the BIS-11 and MCQ. Positive correlations were observed between total BIS-11 scores and volumes of the left anterior cingulate gyrus, left medial frontal gyrus, and left middle frontal gyrus (within the dorsolateral prefrontal cortex [dIPFC]) [29]. In the same study, non-planning impulsivity on the BIS-11 correlated positively with volumes of the left anterior cingulate gyrus, right middle cingulate gyrus, left middle cingulate gyrus, left middle frontal gyrus (within dIPFC), and right orbitofrontal gyrus. BIS-11 attentional impulsivity scores correlated positively with volumes of the left medial frontal gyrus, right medial frontal gyrus, and left middle frontal gyrus (within dIPFC). Positive correlations were observed between MCQ scores and volumes of the right medial frontal gyrus, right orbitofrontal gyrus, left medial frontal gyrus, left anterior cingulate gyrus, and left middle cingulate gyrus; negative correlations were observed between MCQ scores and bilateral ventral putaminal volumes. Taken together, these results suggest regional specificity in the relationships between facets of self-reported impulsivity and gray-matter brain volumes and overlap between the regions linked to BIS-11-assessed and MCQ-assessed impulsivity. A separate study identified negative correlations between left middle frontal gyrus cortical thickness and scores on the BIS-11 and its attentional, motor, and non-planning subscales 
[30]. Negative correlations were also observed between cortical thickness in the orbitofrontal cortex (OFC) and superior frontal gyrus with both overall BIS score and motor impulsivity. The only positive correlation was between the right inferior temporal lobe and non-planning impulsivity. The different results from these two studies could reflect procedural, analytical, or other differences. More studies are needed to investigate the potentially contrasting findings noted above.

Investigations of impulsivity and brain structures have also been conducted in individuals with addictions. Cocaine-dependent individuals have been reported to display lower gray-matter volumes in the $\mathrm{OFC}$, right inferior frontal gyrus (IFG), right insula, left amygdala, left parahippocampal gyrus, temporal gyrus, and bilateral caudate, and lower white-matter volumes in the left inferior and middle frontal gyri, superior temporal gyrus, right anterior cingulate cortex (ACC), insula, and caudate [31]. "Lack of premeditation" scores on the UPPS-P in cocainedependent individuals was negatively correlated with graymatter volumes in the insula and putamen, and positive correlations were observed between self-report impulsivity on the UPPS-P and gray-matter volumes in the left inferior and middle frontal gyri [31].

Functional brain activity has also been linked to impulsivity in addictions. Decreased resting-state connectivity within the putamen and posterior insula has been related to elevated BIS-11 scores in cocaine-dependent, but not healthy comparison, individuals [32]. In a cocaine-craving functional magnetic resonance imaging (fMRI) task, an association between motor impulsivity scores on the BIS-11 and inhibition-related activations in the right IFG and pre-supplementary motor area was observed in abstinent cocaine users [32]. More research is needed to examine the extent to which such findings might relate to clinically relevant measures like vulnerability to relapse.

\section{Response Impulsivity}

\section{Human Studies}

Regions implicated in response impulsivity include the PFC, OFC, anterior insula, ACC, striatum, and frontal gyri [28], with functional connectivity between these regions also contributing importantly. On the GNG, connectivity between the dIPFC and gray matter around the bilateral intraparietal sulcus positively modulated mean go-reaction times and connectivity between the medial PFC and posterior cingulate cortex (PCC) negatively modulated mean go-reaction times [33]. Another study reported that the right anterior insula and right superior frontal gyrus were involved in action restraint, and the right anterior insula and right middle frontal gyrus were involved in action cancellation [34•]. In the latter study, investigators used transcranial theta-burst stimulation in healthy control individuals to selectively disrupt the right anterior insula, right superior frontal gyrus, or right middle frontal gyrus independently. Disruption of the right anterior insula resulted in decreased restraint and cancellation, disruption of the right superior frontal gyrus resulted in decreased restraint, and disruption of the right middle frontal gyrus had no effect on task performance [34•]. In a separate study, Steele et al. [35] compared correctly inhibited no-go trials in the go/no-go task to correct go trials. During response inhibition, regions particularly implicated in successfully inhibiting the response included the fronto-parietal regions, specifically the bilateral ACC and insula, right $\mathrm{OFC}$, right dIPFC, and right supplementary motor areas. During GNG performance, response inhibition was related to increased activation in bilateral subgenual cingulate, bilateral occipital gyrus, right inferior parietal lobe, right precuneus, and right putamen [36]. Error processing activated over 30 regions, including the ACC, superior and medial frontal gyri, IFG, superior and middle temporal gyrus, insula, inferior parietal lobule, and precuneus.

Serotonin (5HT) function has been linked to GNG performance. Activation of the left IFG during no-go was greater with citalopram administrations than with acute tryptophan depletion [37]. The IFG during no-go trials displayed an interaction between type of 5HT challenge and neocortical $5 \mathrm{HT}_{2 \mathrm{~A}}$ receptor binding, such that acute tryptophan depletion produced an increase in response during no-go trials in right IFG in subjects with low $5 \mathrm{HT}_{2 \mathrm{~A}}$ binding potential and a decrease in no-go response in those with high $5 \mathrm{HT}_{2 \mathrm{~A}}$ binding potential as measured by positron emission tomography (PET) [37]. Taken together, findings suggest that there may be an optimal level of serotonin, or activation of the $5 \mathrm{HT}_{2 \mathrm{~A}}$ receptor subtype, which allows for successful no-go responses. These findings suggest avenues for pursuit of personalized treatment options relating to impulsivity and $5 \mathrm{HT}_{2 \mathrm{~A}}$ receptor function.

Recently, a human four-choice serial reaction time task has been developed as a novel translational analog to the rodent 5CSRTT $[38,39]$. During this task, the participant is required to press a button for cue onset, when a green target will appear on the screen. The participant is then required to respond to the green target within an allotted time. Similarly to 5CSRTT, reaction time and premature responding are measured. Interestingly, Worbe et al. [38] found that tryptophan depletion significantly increased premature responding, a finding similar to that in the rodent 5CSRTT. The increase in premature responding was correlated with motor impulsivity on the BIS-11. These results suggest that the 4CSRTT in humans is a valuable new tool that can be used for cross-species translational studies. In addition, these results are also consistent with those from a previous study investigating tryptophan depletion in humans while performing the continuous performance task [40]. Voon et al. [39] found that, compared with healthy volunteers, 
cannabis users, tobacco smokers, and those dependent on either alcohol or methamphetamine showed increased premature responding, consistent with other studies that investigated impulsive action using GNG tasks in groups abusing heroin [41], cocaine [42-44], and tobacco [45], particularly during deprivation [46].

Additionally, GNG performance has been studied with respect to familial alcoholism. Relatively increased activation was observed in the left anterior insula and IFG during successful inhibitions in the family-history-positive group, and these same regions were implicated in greater impulsivity when scans were compared with out of scanner self-reported impulsivity (on the BIS-11) and greater discounting in an experiential discounting task [47•]. Smokers show activation in similar regions when performing a monetary incentive GNG task, such as hyperactivation in the right insula, inferior and middle frontal gyri, dlPFC, and the inferior parietal lobe during inhibition [48]. However, when smokers performed a more standard GNG task, they demonstrated hypoactivity in the left IFG, right medial frontal gyrus, and ACC [48]. Administration of the D2/D3 antagonist haloperidol in smokers during a GNG task resulted in reduced accuracy and reduced activation in the ACC, right superior frontal gyrus, and left IFG [45]. Interestingly, this effect was more pronounced in non-smokers than in smokers, which supports the idea that dopamine is implicated in impulsive action and altered in smokers.

Dopamine also appears relevant to impulsivity in cocaine dependence. In cocaine-dependent individuals, administration of the pro-dopaminergic agent methylphenidate resulted in the restoration of activation in precuneus/posterior cingulate and ventromedial (vmPFC) regions prior to stop errors [49], regions that had been previously implicated in error processing $[50,51]$. Curiously, activation patterns in former cocaine users differed more from those in control individuals performing a GNG task than current users, showing greater activation in the right middle frontal/precentral gyri, right inferior parietal lobe, and left angular/supramarginal gyri [51]. Another study found significantly greater activation within the prefrontal, cingulate, and inferior frontal gyri in abstinent cocaine users for both successful response inhibition and error processing [52]. Taken together, these studies suggest that former cocaine users have greater recruitment of frontal systems while performing inhibitory tasks than both current users and healthy controls. The greater activation may be a compensatory mechanism that may help reduce impulsive actions and assist in maintaining abstinence, particularly as regional activation during inhibitory control has been related to successful abstinence $[53,54]$.

\section{Animal Studies}

Animal studies use analogs to human response impulsivity tasks, including the 5CSRTT, the SST, and the GNG. For example, in rats, inactivation of the vmPFC resulted in impaired inhibition in the 5CSRTT, indicating vmPFC involvement in controlling premature responding [55]. Decreased gray matter in the left accumbens core has been associated with high impulsivity in the 5CSRTT [56•]. Decreased levels of the GABA receptor GAD65/67 in the accumbens core was related to both decreased gray matter in the accumbens core and higher impulsivity, and experimentally reducing GAD65/ 67 receptors in the accumbens core bilaterally in low impulsive animals increased impulsivity [56•]. In line with these findings, inactivation of the accumbens core by the $\mathrm{GABA}_{\mathrm{A}}$ agonist muscimol resulted in global impairments in 5CSRTT performance, and inactivation of the shell induced specific impulse-control deficits [57]. GABAergic projections have been less well investigated in the context of addiction, although GABAergic mechanisms influence function of the mesolimbic pathway [58]. While GABAergic manipulation was successful in modulating response impulsivity in rodents, in humans, GABAergic function has been arguably linked more closely to self-report impulsivity and impulsive choice [59-61] than to response impulsivity (although see Silveri et al. [62]). Within the mesolimbic pathway, dopamine and serotonin have been the two most heavily studied neurotransmitters with regard to impulsivity.

Administration of d-amphetamine, which influences dopaminergic and noradrenergic function, may increase response impulsivity in rodents $[63,64]$. D2-like receptor agonism has been reported to reduce response impulsivity in rats during the 5CSRTT [65], regardless of pre-existing high or low impulsivity levels. Additionally, antagonism of D2-like receptors within the dorsal striatum during SST performance or within the ventral striatum during 5CSRTT performance results in 'normalized' behavior [66, 67], such that D2-like receptor antagonism may stabilize or improve impulsive responding when antagonists are infused directly into those regions; however, there are no alterations in response impulsivity if D2-like receptors are blocked within the PFC [68-71]. Highly impulsive animals, as measured by the 5CSRTT, display low D2like receptor availability in the mesolimbic pathway [72]. Rats with high impulsivity in the 5CSRTT have low D2/D3 expression in the striatum as measured by PET. A relationship between D2/D3 receptor expression and impulsivity was recently reported in humans using PET while participants performed the SST, such that D2/D3 availability was negatively correlated with speed of response inhibition and positively correlated with inhibition-related fMRI activation in frontostriatal circuitry [73•]. Moreover, administration of the D2-like agonist cabergoline in healthy human controls resulted in an increase in stop signal reaction time (decreased response impulsivity) in the SST [74]. Administration of the D2/D3 receptor antagonist nafadotride into the accumbens shell in rats enhanced premature responding in high impulsive rats [75], and rats with lower D2/D3 receptor availability in 
the ventral striatum display greater response impulsivity on the 5CSRTT [76]. These findings further implicate the ventral striatum (more specifically, the nucleus accumbens) in regulating impulsivity, but they additionally highlight the importance of D2-like receptor activation within this region.

Similar to the dopamine system, alterations on impulsivity via the 5HT system can be regionally dependent [77-80]. Global reductions in 5HT (including lesion studies) increase response impulsivity [81, 82]. Mice lacking Tph2 (a manipulation that depletes the brain of serotonin) show impulsive, compulsive, and aggressive behaviors [83] (note that Dambacher et al. [84] found an overlap in motor impulsivity as measured by GNG and aggression in the anterior insula). The elevation in response impulsivity was notably not related to anxiety, and reversal learning was intact. Restoration of 5 HT by treatment with the Tph2 precursor 5hydroxytryptophan resulted in attenuation of increased impulsivity and aggression [83]. Specific 5HT receptors have been related to response impulsivity. In particular, $5 \mathrm{HT}_{1 \mathrm{~A}}$ and $5 \mathrm{HT}_{2 \mathrm{~A} / \mathrm{C}}$ agonists increase response impulsivity $[85,86]$, whereas the $5 \mathrm{HT}_{2 \mathrm{~A}}$ and $5 \mathrm{HT}_{2 \mathrm{~A} / 2 \mathrm{C}}$ receptor antagonists decrease response impulsivity during 5CSRTT performance $[87,88]$. In contrast, the $5 \mathrm{HT}_{2 \mathrm{C}}$ agonist decreases response impulsivity, whereas the $5 \mathrm{HT}_{2 \mathrm{C}}$ antagonist increases response impulsivity $[89,90]$. Increased $5 \mathrm{HT}_{2 \mathrm{C}} \mathrm{R}$ levels in the OFC have been observed in the brains of high-impulsive animals [72]. However, 5HT manipulations have not been particularly beneficial in humans [91-98] (although, see Booij et al. [99], Dougherty et al. [100], LeMarquand et al. [101], Walderhaug et al. [102, 103], and Crean et al. [104], as tryptophan depletion can increase impulsivity), which may be a result of the limitation of serotonergic drugs currently approved for administration in humans. For example, many of the drugs available for administration are selective serotonin reuptake inhibitors that lack specificity for individual receptors, and certain 5HT receptors are currently not targeted in humans in the context of impulsivity. The divergent actions of specific serotonergic receptors highlight the need for more research investigating the roles of different $5 \mathrm{HT}$ receptors and their relationship to different forms of impulsivity.

In addition to dopaminergic and serotonergic contributions to impulsivity, other systems have been implicated. For example, the alpha2-aderenoceptor agonist guanfacine slows SST performance and impairs accuracy, particularly when administered in the dorsomedial (dmPFC) $[68,69,105]$. The norepinephrine inhibitor atomoxetine increases stop-signal reaction times in both rats and humans [69]. While both norepinephrine and dopamine appear important for both error monitoring and performance adjustment, norepinephrine may be more critical in the inhibition of already initiated responses, whereas dopamine may be more important for motor readiness [106].
Impulsive Choice

\section{Human Studies}

Mesocorticolimbic dopamine pathways within the medial PFC (mPFC), OFC, and ventral striatal projections are involved in impulsive choice [107-122]. For example, decreases in white matter in the prefrontal cortex, and increases in the right parahippocampus and hippocampus, have been found in impulsive individuals [123]. The $\mathrm{mPFC}$ has been linked to varying degrees to impulsive choice $[25,124-133]$. In humans, the subjective value of monetary rewards has been associated with activation of the ventral striatum (VS), mPFC, and PCC. During in-scanner delay-discounting performance, the vmPFC was active during the delay period and during choice, which is consistent with a role for the vmPFC in time coding and subjective value. The VS showed a similar pattern, particularly in impulsive participants. The anterior PFC (aPFC) showed a decrease of delayrelated choice activation, but it was selective in impulsive individuals. Additionally, functional connectivity analyses indicated that both vmPFC and aPFC moderated VS activation in different fashions, such that $\mathrm{VmPFC}$ activation resulted in an increase in VS activation whereas the aPFC activation results in a deactivation of the VS [134].

Monetary delay discounting studies have found that drug addiction is associated with elevations in impulsive choice [12, 135-139]. Such patterns of impulsive choice have been observed well into abstinence; for example, cocaine users who were abstinent at least 30 days did not discount rewards differently from those currently using cocaine [140], and heroin users who were abstinent at least 16 months were also indistinguishable on this measure from current users [141]. Interestingly, modafinil administration improved delay discounting in alcohol-dependent individuals by enhancing recruitment of frontoparietal regions, reducing recruitment of the vmPFC and enhancing functional connectivity between the superior frontal gyrus and VS [142]. While different drugs of abuse may differentially alter brain functioning and ultimately impulsive choice in individuals with addictions, pharmacological manipulation of the same brain regions implicated in impulsive choice in both healthy and addicted individuals (e.g., vmPFC, frontoparietal, and striatal regions) may provide assistance in reversing (potentially) drug-induced elevations in impulsivity.

Work investigating relationships between cannabis use and impulsive choice has not found differences between users and nonusers [143] in discounting rates; however, those seeking treatment for cannabis dependence tend to increase impulsivity over time in the absence of contingency management [142]. It is difficult to determine whether the increase in 
impulsive choice is related to cigarette use (instead of cannabis, particularly since nearly all of the cannabis users studied were also tobacco smokers). Additionally, as reported earlier, tobacco-smoking deprivation may exacerbate impulsive action [46], and perhaps the same is true for impulsive action and cannabis use. Studies have begun to investigate crosscommodity discounting of rewards in relationship to addictions. While smokers did not show differences in discounting between monetary and cigarette rewards, the different commodities activated different circuitry. The choice of smaller versus larger rewards, regardless of reward type, activated the $\mathrm{mPFC}$, anterior insula, middle temporal gyrus, middle frontal gyrus, and cingulate gyrus in smokers. The choice of monetary over cigarette rewards was associated with lateralized activation patterns, with cigarette choices primarily involving activation of the PCC, medial and middle frontal gyri, and the precentral gyrus in the left hemisphere, and monetary choices involving activation of VS, temporoparietal cortex, and angular gyrus in the right hemisphere [144•]. These findings resonate with others suggesting lateralization of reward processing networks [145, 146]. Additionally, it appears that contingency management might provide some sort of protection toward elevations in impulsivity and may provide assistance in maintaining abstinence.

\section{Animal Studies}

Alterations in delay discounting are often studied after acute drug exposure; however, cocaine administration may cause long-lasting elevations in impulsive choice as measured by delay discounting [27, 147, 148], a finding consistent with the human literature mentioned above. Perhaps the most compelling evidence for long-term alterations in impulsive choice as a result of cocaine exposure is in rhesus monkeys. Hamilton et al. [149] investigated monkeys that had been exposed to cocaine in utero and found that the males displayed elevated impulsive choice in delay discounting $14-15$ years later; however, it is still unclear how cocaine may alter brain functioning to result in such long-term alterations in impulsive choice.

In rodents, d-amphetamine-induced elevations in dopamine signaling decrease impulsive choice [150]. Rats with high levels of impulsive choice show low levels of D2 dopamine receptor messenger RNA (mRNA) expression in the mPFC [64]. 5HT appears particularly relevant to the 'waiting' aspect of impulsive choice, as depletion of 5HT results in increases in impulsive choice, and the extracellular content in the dorsal raphe increases when animals are waiting. 5HT may also signal proximity or likelihood of rewards, especially in the OFC given data linking OFC function to subjective value determination [106, 151-153]. Global reductions in
5HT have mixed results on impulsive choice, with some studies reporting increases and others reporting decreases in impulsive choice [154-158]. Mixed results may reflect contributions from different $5 \mathrm{HT}$ receptors, with possible different contributions from $5 \mathrm{HT}_{1 \mathrm{~A}}$ [154], $5 \mathrm{HT}_{1 \mathrm{~B}}$ [159], and $5 \mathrm{HT}_{2 \mathrm{~B} / \mathrm{C}}[160]$ receptors.

Noradrenergic contributions to impulsive choice have been suggested. The alpha2-adrenoceptor agonist guanfacine, when injected into the ventral hippocampus, decreased delay discounting, while the dopamine D1-like agonist SCH23390 had no effect (although administration of this agonist may alter impulsivity when administered elsewhere in the brain $[161,162])$, and the GABA receptor agonists muscimol and baclofen increased delay discounting. Given projections from the hippocampus to the amygdala $[163,164]$, these findings may have implications for context-induced emotional influences on decision making.

\section{Summary and Conclusions}

Multiple brain regions have been associated with impulsivity across self-report, response, and choice domains. Other regions show stronger associations with specific facets of impulsivity. Therefore, a basic underlying 'core' circuit may underlie the drive and/or inhibition of basic motivated behaviors, with additional regions influencing this circuitry and leading to specific forms of impulsivity.

Although the current review focuses on self-reported, choice, and response impulsivity, other domains may exist that relate to reflection and decision making [28]. Additionally, impulsivity may be context and emotion dependent, and use of instruments like the UPPS-P scale (which can assess both positive and negative urgency) and the Difficulties in Emotion Regulation Scale may provide insights into such tendencies $[165,166]$.

While brain imaging has facilitated an understanding of the brain biology underlying impulsivity, one should be cognizant of limitations of each approach. That being said, improvements in image acquisition and analysis continue to be made and should be integrated into research as they become available. Of particular importance will be the integration of multiple forms of imaging that offer complementary information with clinically relevant measures. Translational research (from pre-clinical research to clinical research and from research settings into community clinics) will be important with respect to using the information gained about impulsivity to generate improved policy, prevention efforts, and treatments.

Acknowledgments The authors would like to thank Gretchen M. Sprow and Elise E. DeVito for valuable feedback regarding the creation of the manuscript. 


\section{Compliance with Ethics Guidelines}

Conflict of Interest Marci R. Mitchell does not have any conflicts of interest to declare. The authors report no conflicts of interest. Dr. Potenza has consulted for and advised Boehringer Ingelheim, Lundbeck, Ironwood, INSYS and Shire; has financial interests in Somaxon; has received research support from the National Institutes of Health, Veteran's Administration, Mohegan Sun Casino, the National Center for Responsible Gaming and its affiliated Institute for Research on Gambling Disorders, and Forest Laboratories pharmaceuticals; has participated in surveys, mailings, or telephone consultations related to drug addiction, impulse control disorders, or other health topics; has consulted for gambling and legal entities on issues related to addictions or impulse control disorders; has provided clinical care in the Connecticut Department of Mental Health and Addiction Services Problem Gambling Services Program; has performed grant reviews for the National Institutes of Health and other agencies; has guest-edited journal sections; has given academic lectures in grand rounds, $\mathrm{CME}$ events, and other clinical or scientific venues; and has generated books or book chapters for publishers of mental health texts. The manuscript was generated independently of these efforts and while some of the thematic content (relating to impulsivity and addictions) may be shared, they represent independent endeavors.

Supported by: R01DA020908 (MNP), P20DA027844 (MNP), R01DA035058 (MNP), P50DA09241 (MNP), Connecticut Department of Mental Health and Addiction Services, the Connecticut Mental Health Center, and the National Center for Responsible Gaming. MR Mitchell is supported by T32DA007238 (Petrakis, PI), and K12DA031050 (Mazure, PI) from NIDA, NIAAA, Office of Research on Women's Health (ORWH) and NIH Office of the Director (OD). The content of this manuscript was generated by the authors, was not influenced by the funding agencies, and may not reflect the views of the funding agencies.

Human and Animal Rights and Informed Consent This article does not contain any studies with human or animal subjects performed by the author.

\section{References}

Papers of particular interest, published recently, have been highlighted as:

- Of importance

1. Moeller FG, Barratt ES, Dougherty EM, et al. Psychiatric aspects of impulsivity. Am J Psychiatry. 2001;158(11):1783-93.

2. Hinslie L, Shatzky J. Psychiatric Dictionary, Edited. New York: Oxford University Press. 1940.

3. Evenden J. Impulsivity: a discussion of clinical and experimental findings. J Psychopharmacol. 1999;13(2):180-92.

4. Broos N, Schmaal L, Wiskerke J, et al. The relationship between impulsive choice and impulsive action: a cross-species translational study. PLoS One. 2012;7(5):e36781. Comparable tasks were used in both humans and rodents to investigate specific forms of impulsivity across species.

5. Bornovalova MA, Lejuez CW, Daughters SB, et al. Impulsivity as a common process across borderline personality and substance use disorders. Clin Psychol Rev. 2005;25(6):790-812.

6. Ersche KD, Turton AJ, Pradhan S, et al. Drug addiction endophenotypes: impulsive versus sensation-seeking personality traits. Biol Psychiatry. 2010;68(8):770-3.
7. Housden CR, O'Sullivan SS, Joyce EM, et al. Intact reward learning but elevated delay discounting in Parkinson's disease patients with impulsive-compulsive spectrum behaviors. Neuropsychopharmacology. 2010;35(11):2155-64.

8. Swann AC. Impulsivity in mania. Curr Psychiatry Rep. 2009;11(6):481-7.

9. Winstanley CA, Eagle DM, Robbins TW. Behavioral models of impulsivity in relation to ADHD: translation between clinical and preclinical studies. Clin Psychol Rev. 2006;26(4):379-95.

10. Fillmore MT, Rush CR. Impaired inhibitory control of behavior in chronic cocaine users. Drug Alcohol Depend. 2002;66(3):265-73.

11. Moeller FG, Dougherty DM, Barratt ES, et al. Increased impulsivity in cocaine dependent subjects independent of antisocial personality disorder and aggression. Drug Alcohol Depend. 2002;68(1):105-11.

12. Coffey SF, Gudleski GD, Saladin ME, Brady KT. Impulsivity and rapid discounting of delayed hypothetical rewards in cocainedependent individuals. Exp Clin Psychopharmacol. 2003;11(1): $18-25$.

13. Vuchinich RE, Simpson CA. Hyperbolic temporal discounting in social drinkers and problem drinkers. Exp Clin Psychopharmacol. 1998;6(3):292-305.

14. Kirby KN, Petry NM. Heroin and cocaine abusers have higher discount rates for delayed rewards than alcoholics or non-drugusing controls. Addiction. 2004;99(4):461-71.

15. Liao DL, Huang CY, Hu S, et al. Cognitive control in opioid dependence and methadone maintenance treatment. PLoS One. 2014;9(4):e94589.

16. Mitchell SH. Measures of impulsivity in cigarette smokers and non-smokers. Psychopharmacology (Berl). 1999;146(4):455-64.

17. Patton JH, Stanford MS, Barratt ES. Factor structure of the Barratt impulsiveness scale. J Clin Psychol. 1995;51(6):768-74.

18. Reid RC, Cyders MA, Moghaddam JF, Fong TW. Psychometric properties of the Barratt Impulsiveness Scale in patients with gambling disorders, hypersexuality, and methamphetamine dependence. Addict Behav 2013.

19. Whiteside SP, Lynam DR. Understanding the role of impulsivity and externalizing psychopathology in alcohol abuse: application of the UPPS impulsive behavior scale. Exp Clin Psychopharmacol. 2003;11(3):210-7.

20. Greenberg LM, Waldman ID. Developmental normative data on the test of variables of attention (T.O.V.A.). J Child Psychol Psychiatry. 1993;34(6):1019-30.

21. Hogg J, Evans PLC. Stimulus generalization following extradimensional training in educationally subnormal (severely) children. Br J Psychol. 1975;66(May):211-24.

22. Rosvold HE, Mirsky AF, Sarason I, et al. A continuous performance test of brain damage. J Consult Psychol. 1956;20:343-50.

23. Adriani W, Laviola G. Elevated levels of impulsivity and reduced place conditioning with d-amphetamine: two behavioral features of adolescence in mice. Behav Neurosci. 2003;117(4):695-703.

24. Steinberg L, Graham S, O'Brien L, et al. Age differences in future orientation and delay discounting. Child Dev. 2009;80(1):28-44.

25. Dalley JW, Cardinal RN. TW Robbins Prefrontal executive and cognitive functions in rodents: neural and neurochemical substrates. Neurosci Biobehav Rev. 2004;28(7):771-84.

26. Evenden JL, Ryan CN. The pharmacology of impulsive behaviour in rats: the effects of drugs on response choice with varying delays of reinforcement. Psychopharmacology (Berl). 1996;128(2):161-70.

27. Mitchell MR, Weiss VG, Ouimet DJ, et al. Intake-Dependent Effects of Cocaine Self-Administration on Impulsive Choice in a Delay Discounting Task. Behav Neurosci 2014.

28. Fineberg NA, Chamberlain SR, Goudriaan AE, et al. New developments in human neurocognition clinical, genetic, and brain imaging correlates of impulsivity and compulsivity. CNS Spectr. 2014;19(1):69-89. 
29. Cho SS, Pellecchia G, Aminian K, et al. Morphometric correlation of impulsivity in medial prefrontal cortex. Brain Topogr. 2013;26(3):479-87.

30. Schilling C, Kuhn S, Romanowski A, et al. Cortical thickness correlates with impulsiveness in healthy adults. Neuroimage. 2012;59(1):824-30.

31. Moreno-Lopez L, Catena A, Fernandez-Serrano MJ, et al. Trait impulsivity and prefrontal gray matter reductions in cocaine dependent individuals. Drug Alcohol Depend. 2012;125(3):208-14.

32. McHugh MJ, Demers $\mathrm{CH}$, Braud J, et al. Striatal-insula circuits in cocaine addiction: implications for impulsivity and relapse risk. Am J Drug Alcohol Abuse. 2013;39(6):424-32.

33. Sakai H, Uchiyama Y, Shin D, et al. Neural activity changes associated with impulsive responding in the sustained attention to response task. PLoS One. 2013;8(6):e67391.

34. Dambacher F, Sack AT, Lobbestael J, et al. The Role of Right Prefrontal and Medial Cortex in Response Inhibition: Interfering with Action Restraint and Action Cancellation Using Transcranial Magnetic Brain Stimulation. J Cogn Neurosci 2014. Transcranial stimulation was used to selectively disrupt regions during task performance to determine which regions influenced performance of specific aspects of the task.

35. Steele VR, Aharoni A, Munro GE, et al. A large scale $(\mathrm{N}=102)$ functional neuroimaging study of response inhibition in a $\mathrm{Go} /$ NoGo task. Behav Brain Res. 2013;256:529-36.

36. Steele VR, Claus ED, Aharoni E, et al. A large scale $(\mathrm{N}=102)$ functional neuroimaging study of error processing in a $\mathrm{Go} / \mathrm{NoGo}$ task. Behav Brain Res. 2014;268:127-38.

37. Macoveanu J, Hornboll B, Elliott R, et al. Serotonin 2A receptors, citalopram and tryptophan-depletion: a multimodal imaging study of their interactions during response inhibition. Neuropsychopharmacology. 2013;38(6):996-1005.

38. Worbe Y, Savulich G, Voon V, et al. Serotonin depletion induces 'waiting impulsivity' on the human four-choice serial reaction time task: cross-species translational significance. Neuropsychopharmacology. 2014;39(6):1519-26.

39. Voon V, Irvine MA, Derbyshire K, et al. Measuring "waiting" impulsivity in substance addictions and binge eating disorder in a novel analogue of rodent serial reaction time task. Biol Psychiatry. 2014;75(2):148-55.

40. Walderhaug E, Landro NI, Magnusson A. A synergic effect between lowered serotonin and novel situations on impulsivity measured by CPT. J Clin Exp Neuropsychol. 2008;30(2):204-11.

41. Baldacchino A, Balfour DJ, Matthews K. Impulsivity and opioid drugs: differential effects of heroin, methadone and prescribed analgesic medication. Psychol Med 2014: 1-13.

42. Fernandez-Serrano MJ, Perales JC, Moreno-Lopez L, et al. Neuropsychological profiling of impulsivity and compulsivity in cocaine dependent individuals. Psychopharmacology (Berl). 2012;219(2):673-83.

43. Pike E, Stoops WW, Fillmore MR, Rush CR. Drug-related stimuli impair inhibitory control in cocaine abusers. Drug Alcohol Depend. 2013;133(2):768-71.

44. Prisciandaro JJ, Joseph JE, Myrick H, et al. The relationship between years of cocaine use and brain activation to cocaine and response inhibition cues. Addiction 2014.

45. Luijten M, Veltman DJ, Hester R, et al. The role of dopamine in inhibitory control in smokers and non-smokers: a pharmacological fMRI study. Eur Neuropsychopharmacol. 2013;23(10):1247-56.

46. Harrison EL, Coppola S, McKee SE. Nicotine deprivation and trait impulsivity affect smokers' performance on cognitive tasks of inhibition and attention. Exp Clin Psychopharmacol. 2009;17(2): 91-8.

47. DeVito EE, Meda SA, Jiantonio R, et al. Neural correlates of impulsivity in healthy males and females with family histories of alcoholism. Neuropsychopharmacology. 2013;38(10):1854-63.
This study investigated impulsivity in healthy individuals with a family history of alcoholism to determine the potential heritable nature of the nerual processes underlying impulsivity.

48. Luijten M, O'Connor DA, Rossiter S, et al. Effects of reward and punishment on brain activations associated with inhibitory control in cigarette smokers. Addiction. 2013;108(11):1969-78.

49. Matuskey D, Luo X, Zhang S, et al. Methylphenidate remediates error-preceding activation of the default mode brain regions in cocaine-addicted individuals. Psychiatry Res. 2013;214(2):116 21.

50. Bednarski SR, Zhang S, Hong KI, et al. Deficits in default mode network activity preceding error in cocaine dependent individuals. Drug Alcohol Depend. 2011;119(3):e51-7.

51. Castelluccio BC, Meda SA, Muska CE, et al. Error processing in current and former cocaine users. Brain Imaging Behav. 2014;8(1):87-96.

52. Connolly CG, Foxe JJ, Nierenberg J, et al. The neurobiology of cognitive control in successful cocaine abstinence. Drug Alcohol Depend. 2012;121(1-2):45-53.

53. Worhunsky PD, Stevens MC, Carroll KM, et al. Functional brain networks associated with cognitive control, cocaine dependence, and treatment outcome. Psychol Addict Behav. 2013;27(2):47788.

54. Mitchell MR, Balodis IM, Devito EE, et al. A preliminary investigation of Stroop-related intrinsic connectivity in cocaine dependence: associations with treatment outcomes. Am J Drug Alcohol Abuse. 2013;39(6):392-402.

55. Feja M, Koch M. Ventral medial prefrontal cortex inactivation impairs impulse control but does not affect delay-discounting in rats. Behav Brain Res. 2014;264:230-9.

56. Caprioli D, Sawiak SJ, Merlo E, et al. Gamma aminobutyric acidergic and neuronal structural markers in the nucleus accumbens core underlie trait-like impulsive behavior. Biol Psychiatry. 2014;75(2):115-23. This preclinical study investigated how GABA within the accumbens influenced impulsive behavior.

57. Feja M, Hayn L, Koch M. Nucleus accumbens core and shell inactivation differentially affects impulsive behaviours in rats. Prog Neuropsychopharmacol Biol Psychiatry 2014.

58. Hayes DJ, Jupp B, Sawiak SJ, et al. Brain gamma-aminobutyric acid: a neglected role in impulsivity. Eur J Neurosci. 2014;39(11): 1921-32.

59. Deakin JB, Aitken MR, Dowson JH, et al. Diazepam produces disinhibitory cognitive effects in male volunteers. Psychopharmacology (Berl). 2004;173(1-2):88-97.

60. Boy F, Evans CJ, Edden RA, et al. Dorsolateral prefrontal gammaaminobutyric acid in men predicts individual differences in rash impulsivity. Biol Psychiatry. 2011;70(9):866-72.

61. Lee R, Chong B, Coccaro E. Growth hormone responses to GABAB receptor challenge with baclofen and impulsivity in healthy control and personality disorder subjects. Psychopharmacology (Berl). 2011;215(1):41-8.

62. Silveri MM, Sneider JT, Crowley DJ, et al. Frontal lobe gammaaminobutyric acid levels during adolescence: associations with impulsivity and response inhibition. Biol Psychiatry. 2013;74(4): 296-304.

63. Cole BJ, Robbins TW. Effects of 6-hydroxydopamine lesions of the nucleus accumbens septi on performance of a 5-choice serial reaction time task in rats: implications for theories of selective attention and arousal. Behav Brain Res. 1989;33(2):165-79.

64. Simon NW, Beas BS, Montgomery KS, et al. Prefrontal corticalstriatal dopamine receptor mRNA expression predicts distinct forms of impulsivity. Eur J Neurosci. 2013;37(11):1779-88.

65. Fernando AB, Economidou D, Theobald DE, et al. Modulation of high impulsivity and attentional performance in rats by selective direct and indirect dopaminergic and noradrenergic receptor agonists. Psychopharmacology (Berl). 2012;219(2):341-52. 
66. Eagle DM, Wong JC, Allan ME, et al. Contrasting roles for dopamine D1 and D2 receptor subtypes in the dorsomedial striatum but not the nucleus accumbens core during behavioral inhibition in the stop-signal task in rats. J Neurosci. 2011;31(20): 7349-56.

67. Pezze MA, Dalley JW, Robbins TW. Remediation of attentional dysfunction in rats with lesions of the medial prefrontal cortex by intra-accumbens administration of the dopamine $\mathrm{D}(2 / 3)$ receptor antagonist sulpiride. Psychopharmacology (Berl). 2009;202(1-3): 307-13.

68. Bari A, Mar AC, Theobald DE, et al. Prefrontal and monoaminergic contributions to stop-signal task performance in rats. J Neurosci. 2011;31(25):9254-63.

69. Bari A, Robbins TW. Noradrenergic versus dopaminergic modulation of impulsivity, attention and monitoring behaviour in rats performing the stop-signal task: possible relevance to ADHD. Psychopharmacology (Berl). 2013;230(1):89-111.

70. Granon S, Passetti F, Thomas KL, et al. Enhanced and impaired attentional performance after infusion of $\mathrm{D} 1$ dopaminergic receptor agents into rat prefrontal cortex. J Neurosci. 2000;20(3):1208-15.

71. van Gaalen MM, Brueggeman RJ, Bronius PF, et al. Behavioral disinhibition requires dopamine receptor activation. Psychopharmacology (Berl). 2006;187(1):73-85.

72. Besson M, Pelloux Y, Dilleen R, et al. Cocaine modulation of frontostriatal expression of Zif268, D2, and 5-HT2c receptors in high and low impulsive rats. Neuropsychopharmacology. 2013;38(10):1963-73

73. Ghahremani DG, Lee B, Robertson CL, et al. Striatal dopamine $\mathrm{D}(2) / \mathrm{D}(3)$ receptors mediate response inhibition and related activity in frontostriatal neural circuitry in humans. J Neurosci. 2012;32(21):7316-24. The investigation of D2/D3 receptor availablity in humans and its relationship to impulsivity nicely complemented the preclinical study published by Dalley et al. 2007 in Science.

74. Nandam LS, Hester R, Wagner J, et al. Dopamine D(2) receptor modulation of human response inhibition and error awareness. J Cogn Neurosci. 2013;25(4):649-56.

75. Besson M, Belin D, McNamara R, et al. Dissociable control of impulsivity in rats by dopamine $\mathrm{d} 2 / 3$ receptors in the core and shell subregions of the nucleus accumbens. Neuropsychopharmacology. 2010;35(2):560-9.

76. Dalley JW, Fryer TD, Brichard L, et al. Nucleus accumbens D2/3 receptors predict trait impulsivity and cocaine reinforcement. Science. 2007;315(5816):1267-70.

77. Winstanley CA. The utility of rat models of impulsivity in developing pharmacotherapies for impulse control disorders. $\mathrm{Br} \mathrm{J}$ Pharmacol. 2011;164(4):1301-21.

78. Fineberg NA, Potenza MN, Chamberlain SR, et al. Probing compulsive and impulsive behaviors, from animal models to endophenotypes: a narrative review. Neuropsychopharmacology. 2010;35(3):591-604.

79. Dalley JW, Roiser JP. Dopamine, serotonin and impulsivity. Neuroscience. 2012;215:42-58.

80. Pattij T, Vanderschuren LJ. The neuropharmacology of impulsive behaviour. Trends Pharmacol Sci. 2008;29(4):192-9.

81. Harrison AA, Everitt BJ, Robbins TW. Central 5-HT depletion enhances impulsive responding without affecting the accuracy of attentional performance: interactions with dopaminergic mechanisms. Psychopharmacology (Berl). 1997;133(4):329-42.

82. Winstanley CA, Theobald DE, Dalley JW, et al. 5-HT2A and 5HT2C receptor antagonists have opposing effects on a measure of impulsivity: interactions with global 5-HT depletion. Psychopharmacology (Berl). 2004;176(3-4):376-85.

83. Angoa-Perez M, Kane MJ, Briggs DI, et al. Genetic depletion of brain 5HT reveals a common molecular pathway mediating compulsivity and impulsivity. J Neurochem. 2012;121(6):974-84.
84. Dambacher F, Sack AT, Lobbestael J, et al. Out of control Evidence for anterior insula involvement in motor impulsivity and reactive aggression. Soc Cogn Affect Neurosci 2014.

85. Carli M, Samanin R. The 5-HT(1A) receptor agonist 8-OH-DPAT reduces rats' accuracy of attentional performance and enhances impulsive responding in a five-choice serial reaction time task: role of presynaptic 5-HT(1A) receptors. Psychopharmacology (Berl). 2000;149(3):259-68

86. Koskinen T, Ruotsalainen S, Puumala T, et al. Activation of 5HT2A receptors impairs response control of rats in a five-choice serial reaction time task. Neuropharmacology. 2000;39(3):47181.

87. Higgins GA, Enderlin M, Haman M, Fletcher PJ. The 5-HT2A receptor antagonist M100,907 attenuates motor and impulsivetype' behaviours produced by NMDA receptor antagonism. Psychopharmacology (Berl). 2003;170(3):309-19.

88. Ruotsalainen S, Sirvio J, Jakala P, et al. Differential effects of three 5-HT receptor antagonists on the performance of rats in attentional and working memory tasks. Eur Neuropsychopharmacol. 1997;7(2):99-108.

89. Navarra R, Comery TA, Graf R, et al. The 5-HT(2C) receptor agonist WAY-163909 decreases impulsivity in the 5-choice serial reaction time test. Behav Brain Res. 2008;188(2):412-5.

90. Higgins GA, Ouagazzal AM, Grottick AJ. Influence of the 5HT(2C) receptor antagonist SB242,084 on behaviour produced by the 5-HT(2) agonist Ro60-0175 and the indirect 5-HT agonist dexfenfluramine. Br J Pharmacol. 2001;133(4):459-66.

91. Del-Ben CM, Deakin JF, McKie S, et al. The effect of citalopram pretreatment on neuronal responses to neuropsychological tasks in normal volunteers: an FMRI study. Neuropsychopharmacology. 2005;30(9):1724-34.

92. Chamberlain SR, Muller U, Blackwell AD, et al. Neurochemical modulation of response inhibition and probabilistic learning in humans. Science. 2006;311(5762):861-3.

93. Wingen M, Kuypers KP. Ramaekers JG The role of 5-HT1a and 5HT2a receptors in attention and motor control: a mechanistic study in healthy volunteers. Psychopharmacology (Berl). 2007;190(3): $391-400$.

94. Iwamoto K, Takahashi M, Nakamura Y, et al. The effects of acute treatment with paroxetine, amitriptyline, and placebo on driving performance and cognitive function in healthy Japanese subjects: a double-blind crossover trial. Hum Psychopharmacol. 2008;23(5):399-407.

95. Drueke B, Boecker M, Schlaegel S, et al. Serotonergic modulation of response inhibition and re-engagement? Results of a study in healthy human volunteers. Hum Psychopharmacol. 2010;25(6): 472-80.

96. Overtoom CC, Bekker EM, van der Molen MW, et al. Methylphenidate restores link between stop-signal sensory impact and successful stopping in adults with attention-deficit/hyperactivity disorder. Biol Psychiatry. 2009;65(7):614-9.

97. Vollm B, Richardson P, McKie S, et al. Neuronal correlates and serotonergic modulation of behavioural inhibition and reward in healthy and antisocial individuals. J Psychiatr Res. 2010;44(3): 123-31.

98. Chamberlain SR, Muller U, Deakin JB, et al. Lack of deleterious effects of buspirone on cognition in healthy male volunteers. J Psychopharmacol. 2007;21(2):210-5.

99. Booij L, Swenne CA, Brosschot JF, et al. Tryptophan depletion affects heart rate variability and impulsivity in remitted depressed patients with a history of suicidal ideation. Biol Psychiatry. 2006;60(5):507-14.

100. Dougherty DM, Marsh DM, Mathias CW, et al. The effects of alcohol on laboratory-measured impulsivity after L: -Tryptophan depletion or loading. Psychopharmacology (Berl). 2007;193(1): $137-50$. 
101. LeMarquand DG, Benkelfat C, Pihl RO, et al. Behavioral disinhibition induced by tryptophan depletion in nonalcoholic young men with multigenerational family histories of paternal alcoholism. Am J Psychiatry. 1999;156(11):1771-9.

102. Walderhaug E, Lunde H, Nordvik JE, et al. Lowering of serotonin by rapid tryptophan depletion increases impulsiveness in normal individuals. Psychopharmacology (Berl). 2002;164(4):385-91.

103. Walderhaug E, Magnusson A, Neumeister A, et al. Interactive effects of sex and 5-HTTLPR on mood and impulsivity during tryptophan depletion in healthy people. Biol Psychiatry. 2007;62(6):593-9.

104. Crean J, Richards JB, de Wit H. Effect of tryptophan depletion on impulsive behavior in men with or without a family history of alcoholism. Behav Brain Res. 2002;136(2):349-57.

105. Bari A, Eagle DM, Mar AC, et al. Dissociable effects of noradrenaline, dopamine, and serotonin uptake blockade on stop task performance in rats. Psychopharmacology (Berl). 2009;205(2): 273-83.

106. Bari A, Robbins TW. Inhibition and impulsivity: behavioral and neural basis of response control. Prog Neurobiol. 2013;108:44-79.

107. Mariano TY, Bannerman DM, McHugh SB, et al. Impulsive choice in hippocampal but not orbitofrontal cortex-lesioned rats on a nonspatial decision-making maze task. Eur J Neurosci. 2009;30(3):472-84.

108. McClure SM, Laibson DI, Loewenstein G, Cohen JD. Separate neural systems value immediate and delayed monetary rewards. Science. 2004;306(5695):503-7.

109. Jo S, Kim KU, Lee D, Jung MW. Effect of orbitofrontal cortex lesions on temporal discounting in rats. Behav Brain Res. 2013;245:22-8.

110. Mar AC, Walker AL, Theobald DE, et al. Dissociable effects of lesions to orbitofrontal cortex subregions on impulsive choice in the rat. J Neurosci. 2011;31(17):6398-404.

111. Mobini S, Body S, Ho MY, et al. Effects of lesions of the orbitofrontal cortex on sensitivity to delayed and probabilistic reinforcement. Psychopharmacology (Berl). 2002;160(3):290-8.

112. Roesch MR, Calu DJ, Burke KA, Schoenbaum G. Should I stay or should I go? Transformation of time-discounted rewards in orbitofrontal cortex and associated brain circuits. Ann N Y Acad Sci. 2007;1104:21-34.

113. Zeeb FD, Floresco SB, Winstanley CA. Contributions of the orbitofrontal cortex to impulsive choice: interactions with basal levels of impulsivity, dopamine signalling, and reward-related cues. Psychopharmacology (Berl). 2010;211(1):87-98.

114. Valencia-Torres L, Olarte-Sanchez CM, da Costa Araujo S, et al. Nucleus accumbens and delay discounting in rats: evidence from a new quantitative protocol for analysing inter-temporal choice. Psychopharmacology (Berl). 2012;219(2):271-83.

115. Galtress T, Kirkpatrick K. The role of the nucleus accumbens core in impulsive choice, timing, and reward processing. Behav Neurosci. 2010;124(1):26-43.

116. da Costa Araujo S, Body S, Hampson CL, et al. Effects of lesions of the nucleus accumbens core on inter-temporal choice: further observations with an adjusting-delay procedure. Behav Brain Res. 2009;202(2):272-7.

117. Ballard K, Knutson B. Dissociable neural representations of future reward magnitude and delay during temporal discounting. Neuroimage. 2009;45(1):143-50.

118. Bezzina G, Body S, Cheung TH, et al. Effect of disconnecting the orbital prefrontal cortex from the nucleus accumbens core on intertemporal choice behaviour: a quantitative analysis. Behav Brain Res. 2008;191(2):272-9.

119. Diekhof EK, Nerenberg L, Falkai P, et al. Impulsive personality and the ability to resist immediate reward: an fMRI study examining interindividual differences in the neural mechanisms underlying self-control. Hum Brain Mapp. 2012;33(12):2768-84.
120. Abela AR, Chudasama Y. Dissociable contributions of the ventral hippocampus and orbitofrontal cortex to decision-making with a delayed or uncertain outcome. Eur J Neurosci. 2013;37(4):640-7.

121. Bezzina G, Cheung TH, Asgari K, et al. Effects of quinolinic acidinduced lesions of the nucleus accumbens core on inter-temporal choice: a quantitative analysis. Psychopharmacology (Berl). 2007;195(1):71-84.

122. Acheson A, Farrar AM, Patak M, et al. Nucleus accumbens lesions decrease sensitivity to rapid changes in the delay to reinforcement. Behav Brain Res. 2006;173(2):217-28.

123. $\mathrm{Yu}$ R. Regional white matter volumes correlate with delay discounting. PLoS One. 2012;7(2):e32595.

124. Cardinal RN, Pennicott DR, Sugathapala CL, et al. Impulsive choice induced in rats by lesions of the nucleus accumbens core. Science. 2001;292(5526):2499-501.

125. Churchwell JC, Morris AM, Heurtelou NM, Kesner RP. Interactions between the prefrontal cortex and amygdala during delay discounting and reversal. Behav Neurosci. 2009;123(6): 1185-96.

126. Loos M, Pattij T, Janssen MC, et al. Dopamine receptor D1/D5 gene expression in the medial prefrontal cortex predicts impulsive choice in rats. Cereb Cortex. 2010;20(5):1064-70.

127. Perry JL, Joseph JE, Jiang Y, et al. Prefrontal cortex and drug abuse vulnerability: translation to prevention and treatment interventions. Brain Res Rev. 2011;65(2):124-49.

128. Weissenborn R, Robbins TW, Everitt BJ. Effects of medial prefrontal or anterior cingulate cortex lesions on responding for cocaine under fixed-ratio and second-order schedules of reinforcement in rats. Psychopharmacology (Berl). 1997;134(3):242-57.

129. Li N, Ma N, Liu Y, et al. Resting-state functional connectivity predicts impulsivity in economic decision-making. J Neurosci. 2013;33(11):4886-95.

130. Sripada CS, Gonzalez R, Phan KL, Liberzon I. The neural correlates of intertemporal decision-making: contributions of subjective value, stimulus type, and trait impulsivity. Hum Brain Mapp. 2011;32(10):1637-48

131. Gill TM, Castaneda PJ, Janak PH. Dissociable roles of the medial prefrontal cortex and nucleus accumbens core in goal-directed actions for differential reward magnitude. Cereb Cortex. 2010;20(12):2884-99.

132. Carli M, Baviera M, Invernizzi RW, Balducci C. Dissociable contribution of 5-HT1A and 5-HT2A receptors in the medial prefrontal cortex to different aspects of executive control such as impulsivity and compulsive perseveration in rats. Neuropsychopharmacology. 2006;31(4):757-67.

133. Winstanley CA, Theobald DE, Dalley JW, et al. Double dissociation between serotonergic and dopaminergic modulation of medial prefrontal and orbitofrontal cortex during a test of impulsive choice. Cereb Cortex. 2006;16(1):106-14.

134. Jimura K, Chushak MS, Braver TS. Impulsivity and self-control during intertemporal decision making linked to the neural dynamics of reward value representation. J Neurosci. 2013;33(1):344-57.

135. Bickel WK, Marsch LA. Toward a behavioral economic understanding of drug dependence: delay discounting processes. Addiction. 2001;96(1):73-86.

136. Bickel WK, Yi R, Kowal BP, Gatchalian KM. Cigarette smokers discount past and future rewards symmetrically and more than controls: is discounting a measure of impulsivity? Drug Alcohol Depend. 2008;96(3):256-62.

137. Kirby KN, Petry NM, Bickel WK. Heroin addicts have higher discount rates for delayed rewards than non-drug-using controls. J Exp Psychol Gen. 1999;128(1):78-87.

138. Monterosso JR, Ainslie G, Xu J, et al. Frontoparietal cortical activity of methamphetamine-dependent and comparison subjects performing a delay discounting task. Hum Brain Mapp. 2007;28(5):383-93. 
139. Petry NM. Delay discounting of money and alcohol in actively using alcoholics, currently abstinent alcoholics, and controls. Psychopharmacology (Berl). 2001;154(3):243-50.

140. Heil SH, Johnson MW, Higgins ST, Bickel WK. Delay discounting in currently using and currently abstinent cocainedependent outpatients and non-drug-using matched controls. Addict Behav. 2006;31(7):1290-4.

141. Li X, Zhang F, Zhou Y, et al. Decision-making deficits are still present in heroin abusers after short- to long-term abstinence. Drug Alcohol Depend. 2013;130(1-3):61-7.

142. Schmaal L, Goudriaan AE, Joos L, et al. Neural substrates of impulsive decision making modulated by modafinil in alcoholdependent patients. Psychol Med. 2014;44(13):2787-98.

143. McDonald J, Schleifer L, Richards JB, de Wit H. Effects of THC on behavioral measures of impulsivity in humans. Neuropsychopharmacology. 2003;28(7):1356-65.

144. MacKillop J, Amlung MT, Wier LM, et al. The neuroeconomics of nicotine dependence: a preliminary functional magnetic resonance imaging study of delay discounting of monetary and cigarette rewards in smokers. Psychiatry Res. 2012;202(1):20-9. This study investigated delay discounting in smokers, showing the importance of considering commodity when investigating the neural correlates of impulsivity.

145. Spati J, Chumbley J, Brakowski J, et al. Functional lateralization of the anterior insula during feedback processing. Hum Brain Mapp. 2014;35(9):4428-39.

146. Martin-Soelch C, Szczepanik J, Nugent A, et al. Lateralization and gender differences in the dopaminergic response to unpredictable reward in the human ventral striatum. Eur J Neurosci. 2011;33(9): $1706-15$.

147. Simon NW, Mendez IA, Setlow B. Cocaine exposure causes longterm increases in impulsive choice. Behav Neurosci. 2007;121(3): 543-9.

148. Mendez IA, Simon NW, Hart N, et al. Self-administered cocaine causes long-lasting increases in impulsive choice in a delay discounting task. Behav Neurosci. 2010;124(4):470-7.

149. Hamilton LR, Czoty PW, Nader MA. Behavioral characterization of adult male and female rhesus monkeys exposed to cocaine throughout gestation. Psychopharmacology (Berl). 2011;213(4):799-808.

150. Setlow B, Mendez IA, Mitchell MR, Simon NW. Effects of chronic administration of drugs of abuse on impulsive choice (delay discounting) in animal models. Behav Pharmacol. 2009;20(5-6):380-9.

151. Padoa-Schioppa C, Cai X. The orbitofrontal cortex and the computation of subjective value: consolidated concepts and new perspectives. Ann N Y Acad Sci. 2011;1239:130-7.

152. Schoenbaum G, Takahashi Y, Liu TL, McDannald MA. Does the orbitofrontal cortex signal value? Ann N Y Acad Sci. 2011;1239: 87-99.

153. Wallis JD. Cross-species studies of orbitofrontal cortex and valuebased decision-making. Nat Neurosci. 2012;15(1):13-9.
154. Winstanley CA, Theobald DE, Dalley JW, Robbins TW. Interactions between serotonin and dopamine in the control of impulsive choice in rats: therapeutic implications for impulse control disorders. Neuropsychopharmacology. 2005;30(4):66982.

155. Winstanley CA, Dalley JW, Theobald DE, Robbins TW. Global 5HT depletion attenuates the ability of amphetamine to decrease impulsive choice on a delay-discounting task in rats. Psychopharmacology (Berl). 2003;170(3):320-31.

156. Eagle DM, Lehmann O, Theobald DE, et al. Serotonin depletion impairs waiting but not stop-signal reaction time in rats: implications for theories of the role of 5-HT in behavioral inhibition. Neuropsychopharmacology. 2009;34(5):1311-21.

157. Mobini S, Chiang TJ, Ho MY, et al. Effects of central 5hydroxytryptamine depletion on sensitivity to delayed and probabilistic reinforcement. Psychopharmacology (Berl). 2000;152(4):390-7.

158. Winstanley CA, Bachtell RK, Theobald DE, et al. Increased impulsivity during withdrawal from cocaine self-administration: role for DeltaFosB in the orbitofrontal cortex. Cereb Cortex. 2009;19(2):435-44.

159. van den Bergh FS, Bloemarts E, Groenink L, et al. Delay aversion: effects of 7-OH-DPAT, 5-HT1A/1B-receptor stimulation and Dcycloserine. Pharmacol Biochem Behav. 2006;85(4):736-43.

160. Talpos JC, Wilkinson LS, Robbins RW. A comparison of multiple 5-HT receptors in two tasks measuring impulsivity. J Psychopharmacol. 2006;20(1):47-58.

161. Broos N, Diergaarde L, Schoffelmeer AN, et al. Trait impulsive choice predicts resistance to extinction and propensity to relapse to cocaine seeking: a bidirectional investigation. Neuropsychopharmacology. 2012;37(6):1377-86.

162. Pattij T, Janssen MC, Vanderschuren LJ, et al. Involvement of dopamine $\mathrm{D} 1$ and $\mathrm{D} 2$ receptors in the nucleus accumbens core and shell in inhibitory response control. Psychopharmacology (Berl). 2007;191(3):587-98.

163. Orsini CA, Kim JH, Knapska E, Maren S. Hippocampal and prefrontal projections to the basal amygdala mediate contextual regulation of fear after extinction. J Neurosci. 2011;31(47):17269 77.

164. Kishi T, Tsumori T, Yokota S, Yasui Y. Topographical projection from the hippocampal formation to the amygdala: a combined anterograde and retrograde tracing study in the rat. J Comp Neurol. 2006;496(3):349-68.

165. Gratz KL, Roemer L. Multidimensional assessment of emotion regulation and dysregulation: Development, factor structure, and initial validation of the difficulties in emotion regulation scale. J Psychopathol Behav Assess. 2004;26(1): 41-54.

166. Cyders MA. Impulsivity and the sexes: measurement and structural invariance of the UPPS-P Impulsive Behavior Scale. Assessment. 2013;20(1):86-97. 